\title{
Epidemiological study on body mass index distribution and health awareness among women at an urban tertiary care centre of north India
}

\author{
Kamna Datta, Pooja Gupta*, Pushpa Singh
}

Department of Obstetrics and Gynecology, PGIMER and Dr. RML Hospital, New Delhi, India

Received: 21 January 2019

Accepted: 05 March 2019

\author{
*Correspondence: \\ Dr. Pooja Gupta, \\ E-mail: drpoojagupta1@gmail.com
}

Copyright: () the author(s), publisher and licensee Medip Academy. This is an open-access article distributed under the terms of the Creative Commons Attribution Non-Commercial License, which permits unrestricted non-commercial use, distribution, and reproduction in any medium, provided the original work is properly cited.

\begin{abstract}
Background: Obesity has become a new worldwide health problem and is gradually moving towards an epidemic. overweight and obesity implies an abnormal excessive fat accumulation that poses health risk. According to National Family Health Survey-4, prevalence of obesity has doubled in country over the last decade. Asian Indians stand at higher risk for development of obesity related non-communicable diseases at lower body mass index levels.

Methods: It was an observational interpretive study carried on 1000 randomly selected women over 3 months in a tertiary center of urban northern India. BMI was obtained by dividing weight in kilograms and height in meters squares. Patients were enquired about any menstrual complains, known comorbidities, awareness of obesity in terms of its cause and effects, about weight reduction and benefits of exercise and its practice and details noted in a preformed performa. No prior intervention or health education was given to avoid bias.

Results: Out of 1000 women, mean BMI was found to be $31.85 \pm 8.85 \mathrm{~kg} / \mathrm{m}^{2}$. BMI classification (Asian standards) stated that $8.1 \%$ were overweight and $78 \%$ of patients were pre obese and obese (maximum in age of 21-40 years). Menstrual complaints were present among 39\% of overweight and obese groups. Among comorbidities, hypothyroidism was found to be maximum being $9.5 \%$ in the obese group, followed by hypertension and diabetes mellitus. Only $26.3 \%$ of obese women were aware of the factors causing obesity. Knowledge of exercise benefits was grossly limited, with only one fourth of the pre obese and obese population being aware of it.

Conclusions: Rising obesity in Indian women needs measures for prevention. Though there is knowledge of the cure among Indian females but there is limited ability to implement the same. Health education of women regarding obesity related comorbidities along with the benefits of weight loss with exercises should be promoted strongly.
\end{abstract}

Keywords: BMI, Health awareness, Indian women, Obesity

\section{INTRODUCTION}

Obesity is the fastest growing health problem of present world. Overweight and obesity are defined as abnormal excessive fat accumulation that poses a risk to health. Although, like other developing nations, India is still battling malnutrition, but the country has developed another nutritional problem-obesity-an epidemic of the twentieth century. According to the National Family Health Survey (NFHS-4, 2015-2016) the number of obese people has doubled in past 10 years in the country. Most of the states are experiencing a sharp rise in the number of obese people. The main reason attributed to this rise are adoption of sedentary lifestyle and consumption of energy dense foods. ${ }^{1-4}$ Physical activity levels are low in most Asian Indians as compared to 
white Caucasians. ${ }^{5}$ Sedentary behavior increases in Asian Indians at around 35 to 45 years in women and above 45 years in men. ${ }^{6}$ Obesity is a known risk factor for development of type 2 diabetes mellitus, hypertension, dyslipidemia, coronary heart disease and many cancers like endometrial, colon, breast. ${ }^{7}$ In Asian Indians excess abdominal and hepatic fat is associated with multiple adverse health outcomes. ${ }^{8-10}$ Being a commonly encountered medical problem, obesity also poses challenges in treatment. It is challenging to prepare an appropriate obesity management plan and hence patients experience continuous weight gain over time despite being under regular medical supervision. Current interventions include diet management, physical exercise and psychological support. ${ }^{11}$ However, this is a complex phenomenon, and interventions have limited long-term efficacy because of low adherence over time. ${ }^{12}$ Guidelines for physical activity for Asian Indians recommend a $60 \mathrm{~min}$ of physical activity daily or $\geq 300$ min of weekly moderate intensity physical activity as an effective strategy for weight loss. ${ }^{13}$ But lack of time, facilities for exercise, extremes of climate, social and security reasons are frequently cited as the reasons for inability to do adequate exercise. Health knowledge on exercise including prevention of development of T2DM and cardiovascular disease and improvement in hypertension, dyslipidemia, improvement in bone density and sense of well-being. Benefits of Yogic Asanas on weight loss, if any, is still an area of research. Physical activity levels should be assessed in subsequent visits and patients should be encouraged to increase duration and intensity of exercise to improve weight loss and maintain it over next couple of years. ${ }^{14}$

Body mass index (BMI) or Quetelet index is a noninvasive, time efficient and inexpensive screening tool for the measure of body fat. ${ }^{15}$ The threshold of obesity has been internationally accepted as a BMI of $\geq 30 \mathrm{~kg} / \mathrm{m}^{2}{ }^{16}$

Table 1: Body mass index classes.

\begin{tabular}{|l|l|l|}
\hline $\begin{array}{l}\text { Nutritional } \\
\text { status }\end{array}$ & $\begin{array}{l}\text { WHO criteria } \\
\text { BMI cut off }\end{array}$ & $\begin{array}{l}\text { Asian criteria } \\
\text { BMI cut off }\end{array}$ \\
\hline Underweight & $<18.5$ & $<18.5$ \\
\hline Normal & $18.5-24.9$ & $18.5-22.9$ \\
\hline Overweight & $25-29.9$ & $23-24.9$ \\
\hline Pre-obese & - & $25-29.9$ \\
\hline Obese & $>30$ & $>30$ \\
\hline
\end{tabular}

It is obtained when the weight in kilograms is divided by the square of the height in meters. Nutritional status is determined through BMI cut-offs values as recommended by the World Health Organization (WHO) (Table 1), however, in recent years, the criteria values are modified to fit the Asian pacific body composition, which is claimed to be different compared to the American or European body composition (Table 1). ${ }^{17}$ Thus the "Asian criteria" for the determination of nutritional status is now adopted by several Asian countries including India. So far, several studies have already been conducted to determine the factors that have the greatest impact on South Asian women's BMI. ${ }^{2}$

Need for the study was felt because obesity is a chronic relapsing disease that manifests itself at different life stages in women: childhood, reproductive years and menopausal years and causes significant morbidities. Its assessment and awareness are crucial for leading a healthy lifestyle.

\section{METHODS}

This was a qualitative descriptive-interpretive type of study. An observational study was carried over 1000 patients attending the gynaecology outpatient department of PGIMER and Dr. RML Hospital over a period of 3 months (November 2017 to January 2018). Subjects were randomly selected irrespective of age, ethnicity, religion, region or socioeconomic status. All interviews were carried out at the usual office visit environment. Informed consent was taken from all patients. Interviews were moderated by doctors and the qualitative investigation included the same doctor as an observer. Interviews lasted between 5 to 10 minutes. Height was measured on a standing manual height measuring scale in centimeters and converted to meters with an accuracy of $0.1 \mathrm{~cm}$. Weight was measured in kilograms on routine electronic weighing machine with an accuracy of $10 \mathrm{gm}$. Body mass index BMI was obtained by dividing weight in kilograms and height in meters .Authors decided to use the BMI since it can be quickly determined from the height and weight of the outpatients and the whole process can provide a list of all normal, underweight, overweight, and obese patients within an hour or two after the data is gathered. Patients were enquired about the existence of any menstrual complains. Presence of medical or surgical comorbidities of any nature was noted irrespective of the presence or absence of any menstrual complaint. Careful questionnaire was performed with all patients regarding the awareness of obesity in terms of its cause and effects, awareness about weight reduction, exercise if conducted and awareness regarding the benefits of exercise. All the data was gathered and put together in a preformed questionnaire. Being an observational study, no intervention or any form of health education was given to avoid any bias in the questionnaire done.

\section{Statistical analysis}

Data was compiled and statistically analyzed using SPSS Software 20.0.

\section{RESULTS}

Out of 1000 outpatients questioned, the mean age of study patients was $36.10 \pm 13.05$ years. Mean height in meters was obtained as 1.53 meters, mean weight in kilograms as $61.59 \mathrm{~kg} \pm 0.46$ and mean BMI was $31.85 \pm 8.85 \mathrm{~kg} / \mathrm{m}^{2}$ (Table 2 ). 
Table 2: Mean values of height, weight, body mass index (BMI).

\begin{tabular}{|l|l|l|l|}
\hline & Minimum & Maximum & Mean \\
\hline Age(years) & 13 & 88 & 36.13 \\
\hline Height $($ meters $)$ & 1.00 & 1.80 & 1.53 \\
\hline Weight $(\mathrm{kg})$ & 24 & 110 & 61.59 \\
\hline BMI $\left(\mathrm{kg} / \mathrm{m}^{2}\right)$ & 10.50 & 88.25 & 31.85 \\
\hline
\end{tabular}

On classification of patients according to BMI (as per Asian standards for BMI), it was observed that $1.9 \%$ were underweight, $12 \%$ had normal BMI, $8.1 \%$ were overweight, $26.5 \%$ pre-obese and $51.5 \%$ were obese (Table 3).
Table 3: Distribution of BMI classes (as per Asian standards) in study population.

\begin{tabular}{|l|l|}
\hline BMI categories & Percentage \\
\hline Underweight & 1.9 \\
\hline Normal & 12 \\
\hline Overweight & 8.1 \\
\hline Preobese & 26.5 \\
\hline Obese & 51.5 \\
\hline
\end{tabular}

With stratification of patients into various age groups, the maximum number of obese were found in the reproductive age group 21-40 years $(59.2 \%)$, followed by 41-60 years $(31 \%)$ (Table 4$)$.

Table 4: Distribution of females in BMI classes as per age groups.

\begin{tabular}{|l|l|l|l|l|l|l|l|}
\hline & & \multicolumn{3}{c|}{ BMI classes } & & \\
& & Underweight & Normal & Overweight & Pre obese & Obese \\
\hline & Less than 20 years & 3 & 15 & 4 & 16 & 24 & 62 \\
\hline \multirow{3}{*}{ Age groups } & 21-40 years & 11 & 81 & 50 & 173 & 305 & 620 \\
\hline & 41-60 years & 5 & 21 & 20 & 64 & 160 & 270 \\
\hline \multirow{2}{*}{ Total } & More than 60 years & 0 & 3 & 7 & 12 & 26 & 48 \\
\hline
\end{tabular}

It was further noted that $10 \%(2 / 19)$ of underweight, $21 \%$ (24/120) of normal BMI, 39\% (32/81) of overweight and $40.5 \%(101 \pm 211 / 265 \pm 515)$ of the pre-obese and obese group suffered from menstrual complaints. Among menstrual disturbances, highest incidence was of oligomenorrhea $(43.7 \%)$ followed by dysmenorrhea and menorrhagia $(32.2 \%)$ followed by polymenorrhea $(13 \%)$ and polymenorrhagia $(11.1 \%)$.

Being an observational study, no diagnostic tests were performed to identify co existing medical disorders but a detailed history for the same was taken. It was found that among patients observed, $26 \%$ of overweight and obese group suffered from medical comorbidities mainly in the forms of hypertension, diabetes mellitus, anemia, dyslipidemia and hypothyroidism. Nearly $10 \%$ of all females enrolled in the study came to the OPD for management of infertility. It was noted that almost $60 \%$ $(55 / 92)$ of them were in the pre obese and obese category.

Out of the total patients questioned, only $27 \%$ were aware of the causes of obesity like and $21 \%$ knew the effects of it. Overall, only $25.4 \%$ of the patients had knowledge about exercise benefits. Awareness about the benefits of daily exercise is limited in the patient group studied as only $19 \%$ of normal BMI group, $26 \%$ of the pre obese and $25 \%$ of the obese group were aware of it. When authors analysed the data regarding the patients who actually performed physical activity, authors found that only $20.2 \%$ of the patients were involved in physical activity in forms of yoga and workouts. Existence of knowledge of weight reduction by physical activity was found in $2 \%$ of normal BMI group, $16 \%$ of pre obese and $20 \%$ of obese population.

\section{DISCUSSION}

Obesity, also known as the "epidemic of the new millennium" is now one of the most important public health problems we are facing. In the present world, the prevalence of obesity is rising at an alarming rate to such an extent that if the current trajectory continues, almost half of the world's population will become either obese or overweight by $2030 .{ }^{18}$ Obesity is a well recognized cause of non communicable diseases hence as obesity increases so will its effects. In fact, it is more commonly seen in women than in men. Surprisingly the incidence of childhood obesity is too rising rapidly. ${ }^{18}$

According to National Family Health Survey (NFHS)-4 (2015-2016), Andhra Pradesh, Andaman and Nicobar, Puducherry and Sikkim have more than 30 percent of their populations been in the "obese" category. Also, more than 10 per cent population in Bihar, Madhya Pradesh, Meghalaya, Tripura and West Bengal is obese which has doubled since the last National Family Health Survey 3 (2005-06). ${ }^{19}$ The concept of rural urban divide was also introduced. According to NFHS-4, in a state of south India (Andhra Pradesh), 45.6 percent of the urban women were obese against the 27.6 per cent women in rural areas. ${ }^{20}$ Since present study has been conducted in 
the gynaecology outpatient department of a tertiary care centre, data has been gathered for predominantly urban women population only. Authors observed that in present study the prevalence of overweight and obese people was $8 \%$ and $51 \%$ respectively as per Asian standards of BMI classification. The data was in correlation with NFHS 4 data.

In 2005, Kelishadi R et al, performed a population-based study for non-communicable diseases' risk factor surveillance. They concluded that overweight as well as generalized and abdominal obesity were more prevalent in the 45-64 year age group (included males and females both). ${ }^{21}$ In 2016, Girdhar $\mathrm{S}$ et al, conducted an epidemiological survey in the form of a community based cross sectional study in which prevalence and risk factors for obesity were identified. It was observed that the prevalence of overweight $(\mathrm{BMI}=23-24.9)$ and obesity (BMI >25) was $12.7 \%$ and $29.6 \%$ respectively and most of the overweight/obese women belonged to the age group of 41-60 years. They also found that prevalence of obesity increased with increase in age $(P<0.001){ }^{22}$ Rössner et al, also stated the rise in BMI with age and the highest gain in those who reached the age of 50 years and beyond. ${ }^{23}$ Present study focused on female population and found a higher prevalence of overweight and obesity in 41-60 years age group, similar to results shown in previous studies. Unlike previous study by Girdhar et al, authors observed that the prevalence of overweight and obesity was much high $(66.6 \%$ in $41-60$ years followed by $57 \%$ in $21-40$ years age group) in present study. Increase in BMI was found to be significantly associated with the rising age $(\mathrm{p}<0.05)$. This difference in the prevalence could be attributed to the difference in the demographic variables of the representative population, food pattern, urbanization, and the incorporation of Asian standards for BMI in present study. In 2018, Esti Nurwanti et al, have identified a positive and significant effect of sedentary behaviors and unhealthy foods intake on obesity prevalence. The increasing obesity risk in women more than in men denote a possible faulty diet in women in relation to obesity. ${ }^{24}$ Another reason cited for rising obesity with age is post menstrual drop in estrogen as explained by Demissie and Milewicz in 2003. ${ }^{25,26}$ In present study, teenage group represented $6 \%$ of the total study population. Out of this, $6 \%$ were overweight and $38 \%$ were obese. In a study conducted by Dodd JM et al, it was reported that girls who are overweight or obese are less likely to engage in physical activities or exercise programmes that promote energy expenditure and are prone to developing high-risk behaviours. ${ }^{27}$

Apart from increasing the susceptibility to non communicable diseases, obesity has many adverse effects on reproductive health of the women like subfertility, polycystic ovarian disease, menstrual abnormality etc. (28). In a study conducted by Padhye SM, they found that out of the total 608 participants, 243 (40\%) were overweight, $96(15.8 \%)$ were obese. Regarding the common health problems, $154(25.3 \%)$ have sub fertility and $199(32 \%)$ had genitourinary infection. Similarly, 90 (14.8\%) had menstrual problems. Present results were consistent with the above study. Of the total of 1000 participants in present study, 346 suffered from one or more types of AUB in the form of menorrhagia, polymenorrhea, polymenorrhagia and oligomenorrhea. The highest incidence of menstrual complaints was again found in the pre obese and obese group. Also $60 \%$ (55/92) of females who came with complaints of infertility were in the pre obese and obese category.

The increased prevalence of obesity, which was initially more marked in developed countries has become a global concern. ${ }^{15,17,27,29-31}$ Etiology of obesity is complex and multifactorial. The fundamental causes behind increasing obesity are a shift in diet towards increased intake of obesogenic energy dense foods that have high content of sugars, fat and salt but are low in vitamins, minerals and other healthy micronutrients. Along with wrong dietary habbits physical inactivity plays an equally important role. The shift away from the traditional high fiber diet"nutrition transition" and the tendency for a more sedentary lifestyle are believed to contribute to this epidemic. $^{31,32}$

Physical inactivity is becoming part of today's lifestyle causing a rapid increase in the incidence of many diseases including cardiovascular disease, diabetes, and obesity. These chronic diseases are preventable by adopting a healthy lifestyle including regular physical activity. ${ }^{33}$ In 2008 , Healy et al. observed that a reduction in sitting time can improve the metabolic consequences of obesity, regardless of the level of activity. ${ }^{34}$

WHO developed the global strategy on diet, physical activity and health Endorsed by the $57^{\text {th }}$ World health assembly in May 2004, it aims to significantly reduce the prevalence of non communicable diseases and their common risk factors primarily unhealthy diet and physical inactivity. ${ }^{35}$ Despite physical activity having several benefits, a considerable number of people do not engage in sufficient exercise. ${ }^{36}$ This supports present study, as only $20 \%$ of the obese were involved in some forms of exercise to reduce weight. This practice is attributed to scarcity of time as stated by most patients.

Awareness should be created to promote healthy food habits and physical activity. Health education of the patients regarding obesity related comorbidities along with the benefits of weight loss with exercises should be provided. Individual needs two types of physical activity in a week namely aerobic and muscle-strengthening. Achieving more than $30 \mathrm{~min}$ of vigorous activity for five days during the week along with two days of muscle strengthening exercises is recommended for most adults.

\section{CONCLUSION}

We are in an unusual position of facing the greatest epidemic in our history. Rising obesity in Indian women 
needs measures for prevention. Though there is knowledge of the cure but a limited ability to implement the solution. Health education of women regarding obesity related comorbidities along with the benefits of weight loss with exercises should be promoted strongly. There is a desperate need for national programmes targeting awareness, education and improved infrastructure to facilitate healthy lifestyle habits. This is the only key to alleviate the economic and healthcare burden of the disorders related to obesity.

\section{Funding: No funding sources}

Conflict of interest: None declared

Ethical approval: The study was approved by the Institutional Ethics Committee

\section{REFERENCES}

1. De Heer H, Wilkinson AV, Strong LL, Bondy ML, Koehly LM. Sitting time and health outcomes among Mexican origin adults: obesity as a mediator. BMC Public Health. 2012;12:896.

2. Tudor-Locke C, Brashear MM, Johnson WD, Katzmarzyk PT. Accelerometer profile of physical activity in normal weight, overweight and obese US men and women. Int $\mathbf{J}$ Behav Nutr Phys Act. 2010;7:60.

3. Misra A, Khurana L. Obesity and the metabolic syndrome in developing countries. J Clin Endocrinol Metab. 2008;93:S9-30.

4. Misra A, Khurana L. Obesity-related noncommunicable diseases: south Asians vs white Caucasians. Int J Obes (Lond). 2011;35:167-87.

5. Misra A, Sharma R, Gulati S, Joshi SR, Sharma V, Ibrahim A, Joshi S, et al. Consensus dietary guidelines for healthy living and prevention of obesity, the metabolic syndrome, diabetes, and related disorders in Asian Indians. Diabetes Technol Ther. 2011;13:683-94.

6. Singh RB, Pella D, Mechirova V, Kartikey K, Demeester F, Tomar RS, et al. Prevalence of obesity, physical inactivity and undernutrition, a triple burden of diseases during transition in a developing economy. The Five City Study Group. Acta Cardiol. 2007;62;119-27.

7. Alves MG, Moreira Â, Guimarães M, Nora M, Sousa $\mathrm{M}$, Oliveira PF, et al. Body mass index is associated with region-dependent metabolic reprogramming of adipose tissue. BBA Clin. 2017;8:1-6.

8. Carey VJ, Walters EE, Colditz GA, Solomon CG, Willet WC, Rosner BA, et al. Body fat distribution and risk of non-insulin-dependent diabetes mellitus in women the nurses' health study. Am J Epidemiol. 1997;145:614-9.

9. Wang Y, Rimm EB, Stampfer MJ, Willett WC, Hu FB. Comparison of abdominal adiposity and overall obesity in predicting risk of type 2 diabetes among men. Am J Clin Nutr. 2005;81:555-63.

10. Yusuf S, Hawken S, Ounpuu S. Obesity and the risk of myocardial infarction in 27000 participants from
52 countries: a case-control study. Lancet. 2005;366:1640-9.

11. Scottish Intercollegiate Guidelines Network (2010) Management of obesity. a national clinical guideline Edinburgh: SIGN; Available at: http://www.sign.ac.uk/pdf/sign115.pdf.

12. Stevens J, Truesdale KP, McClain JE, Cai J. The definition of weight maintenance. Int $\mathbf{J}$ Obes. 2006;30(3):391-9.

13. Dickinson HO, Mason JM, Nicolson DJ, Campbell F, Beyer FR, Cook JV, et al. Lifestyle interventions to reduce raised blood pressure: a systematic review of randomized controlled trials. J Hypertens. 2006;24(2):215-33.

14. Behl S, Misra A. Management of obesity in adult Asian Indians. Indian Heart J. 2017;69(4):539-44.

15. Barao K, Forones NM. Body mass index: different nutritional status according to WHO, OPAS and Lipschitz classifications in gastrointestinal cancer patients. Arq Gastroenterol. 2012;49(2):169-71.

16. WHO Expert Consultation Appropriate body-mass index for Asian populations and its implications for policy and intervention strategies. Lancet. 2004;363(9403):157-63.

17. Llido LO, Mirasol R. Comparison of body mass index based nutritional status using WHO criteria versus "Asian" criteria: report from the Philippines. PhilSPEN Online J Parenter Enteral Nutr. 2011:1-8.

18. Hruby A, Hu FB. The epidemiology of obesity: a big picture. Pharmacoeconomics. 2015;33(7):673-89.

19. National Family Health Survey (NFHS-3). Available at:https://dhsprogramcom/pubs/pdf/FRIND3/FRIND 3-Vol1[Oct-17-2008]pdf.

20. Dandona R, Pandeya A, Dandonaa L. A review of national health surveys in India. Bulletin of the World Health Organization; Type: Policy and practice Article ID: BLT.15.158493.

21. Kelishadi R, Alikhani S, Delavari A, Alaedini F. Obesity and associated lifestyle behaviours in Iran: findings from the first National non-communicable disease risk factor surveillance survey. Public Health Nutr. 2008;246-51.

22. Girdhar S, Sharma S, Chaudhary A, Bansal P, Satija M. An epidemiological study of overweight and obesity among women in an urban area of north India. Indian J Community Med. 2016;41(2):154-7.

23. Rössner S. Social aspects of obesity. Med. Metab.1998;1;54-7.

24. Nurwanti E, Uddin M, Chang JS, Hadi H, SyedAbdul S, Su EC, et al. Roles of sedentary behaviors and unhealthy foods in increasing the obesity risk in adult men and women: a cross-sectional national study. Nutr. 2018;10(6):31.

25. Demissie M, Milewicz A. Hormonal disorders of new obesity. Diabetol Prakt. 2003;3:207-9.

26. Milewicz A, Tworowska U, Demissie M. Menopausual obesity-myth or fact? Climacteric. 2001;4:273-83.

27. Dodd JM, Turnbull DA, McPhee AJ, Wittert G, Crowther CA, Robinson JS. Limiting weight gain in 
overweight and obese women during pregnancy to improve health outcomes: the LIMIT randomised controlled trial. BMC Preg Childbirth. 2011;11(1):79.

28. Padhye SM. Pattern of body mass index and common health problems in women of reproductive age group in a private clinic in Kathmandu. JNMA J Nepal Med Assoc. 2017;56(207):352-6.

29. Tremblay MS, Willms JD. Secular trends in the body mass index of Canadian children. CMAJ. 2000;163:1429-33.

30. Reilly J. Epidemic of obesity in UK children. Lancet. 1999;354:1874-5.

31. Ojofeitimi EO, Olugbenga-Bello AI, Adekanle DA, Adeomi AA. Pattern and determinants of obesity among adolescent females in private and public schools in the Olorunda Local Government Area of Osun State, Nigeria: a comparative study. J Public Health Africa. 2011;2(1):e11.

32. Hawkes C. Uneven dietary development: linking the policies and processes of globalization with the nutrition transition, obesity and diet-related chronic diseases. Global Health. 2006;28:2-4.
33. Elloumi L, van Beijnum BJ, Hermens H. Exploratory study of a virtual community for physical activity. Health Technol (Berl). 2018;8(1):81-95.

34. Healy GN, Wijndaele K, Dunstan DW, Shaw JE, Salmon J, Zimmet PZ, et al. Objectively measured sedentary time, physical activity, and metabolic risk: the Australian Diabetes, Obesity and Lifestyle Study (AusDiab). Diabetes Care. 2008;31:369-71.

35. World Health Organization. Global strategy on diet, physical activity and health. 1. Diet 2. Exercise 3. Health promotion 4. National health programs 5. International cooperation. ISBN $92 \quad 4 \quad 159222 \quad 2$ (LC/NLM classification: QT 180).

36. Hayes T, Nahar VK, Sharma M. Predicting physical activity behavior in African American females: using multi theory model. J Res Health Sci. 2018;18(2):e00410.

Cite this article as: Datta K, Gupta P, Singh P. Epidemiological study on body mass index distribution and health awareness among women at an urban tertiary care centre of north India. Int J Reprod Contracept Obstet Gynecol 2019;8:1542-7. 